\title{
An in vitro Assay to Screen for Substrates of PKA Using Phospho-motif-specific Antibodies
}

\author{
David M. Gau* and Partha Roy
}

Dept of Bioengineering, University of Pittsburgh, Pittsburgh, USA

*For correspondence: $\underline{\text { dmg40@pitt.edu }}$

\begin{abstract}
[Abstract] Kinases function as regulators of many cellular processes such as cell migration. These enzymes typically phosphorylate target motif sequences. Mass spec or phospho-specific antibody detection can be used to determine whether a kinase can phosphorylate proteins of interest, however, mass spec can be expensive and phospho-antibodies for the protein of interest may not exist. In this protocol, we will describe an in vitro kinase assay to provide a preliminary readout on whether a protein of interest may be phosphorylated by PKA. Our protein of interest is purified after expression in bacteria and treated with recombinant PKA from bovine heart. Protein is then extracted and a western blot is performed using a phospho-specific antibody for PKA's target motif. This will allow us to quickly determine if it is possible for PKA to phosphorylate our protein of interest.
\end{abstract}

Keywords: Protein Kinase A (PKA), Kinase activity, In vitro, Western blot, Protein phosphorylation

[Background] Hormones and other factors that cause activation of adenylate cyclase through G-linked G-protein coupled receptors (GPCR) and subsequently promote generation of second messenger cAMP can affect cellular processes like cell migration. Elevation of CAMP level leads to activation of PKA, a serine-threonine kinase that plays an important role in the regulation of actin cytoskeletal dynamics in migrating cells. PKA influences different facets of actin cytoskeleton-regulatory processes including modulation activities of a) Rho-family GTPases (Rho, Rac and Cdc42), b) actin-binding proteins (e.g., VASP [vasodilator stimulated phosphoprotein]), c) kinases which indirectly control the function of actinbinding proteins (e.g., p21-activated kinase) and d) myosin (Howe, 2004). PKA and other kinases, however, can also modulate other proteins by phosphorylation that are currently unknown.

There are multiple ways to determine kinase activity on a protein of interest such as mass spec for phosphopeptides, however, such assays can be costly. In this protocol, we will describe the use of an in vitro kinase assay to examine PKA kinase activity on a GST-tagged protein of interest using a phospho-specific antibody for PKA's target motif. Using a PKA motif antibody is advantageous if known phosphorylation sites are unknown on a protein or if no phosphospecific protein antibody exists. While this assay is quick and simple to perform, it depends on the kinase targeting a motif pre-determined by available antibodies and thus limited in potential. A different kinase can be easily tested if an antibody to detect that kinase's phospho motif exists. Despite this, successful readout from this assay can provide motivation to pursue more comprehensive exploration into kinase phosphorylation of a protein of interest. Although this protocol describes usage of recombinant protein purified from bacteria, protein can be obtained from any source (i.e., insect or human cells) but total yield of protein will vary dependent on the source and may need to be optimized. Figure 1 below illustrate the general workflow for this protocol. 


\section{Express Protein $\longrightarrow$ Purify Protein $\longrightarrow$ Kinase Treat $\longrightarrow$ Phospho Protein Analysis}

Figure 1. General protocol workflow for kinase analysis

\section{Materials and Reagents}

1. Eppendorf tubes

2. Bacteria culture tube (Southern Labware, catalog number: 110178)

3. BL21 competent E. coli (New England BioLabs, catalog number: $\mathrm{C} 2530 \mathrm{H}$ )

4. LB Broth (Thermo Fisher, catalog number: 10855001)

5. LB Agar Ampicillin-100 (Sigma-Aldrich, catalog number: L5667)

6. IPTG (Sigma-Aldrich, catalog number: 16758)

7. Ampicillin $100 \mathrm{mg} / \mathrm{ml}$ (Sigma-Aldrich, catalog number: A5354)

8. Glutathione Agarose (Thermo Fisher, Pierce, catalog number: 16100)

9. Protease inhibitor cocktail for bacteria (Sigma-Aldrich, catalog number: P8465)

10. pGEX-4T1 GST-fusion vector (Sigma-Aldrich, catalog number: GE28-9545-49)

11. PBS (Lonza, BioWhittaker, catalog number: BW17516F)

12. IP Lysis Buffer (Thermo Fisher, Pierce, catalog number: 87787)

13. PKA (Sigma-Aldrich, catalog number: P2645-400UN)

14. Laemmli SDS sample buffer, reducing 6x (Alfa Aesar, catalog number: J61337-AC)

15. BES (Thermo Fisher, BioReagents, catalog number: BP501500)

16. EGTA (Tocris Bioscience, catalog number: 28-071-G)

17. $\mathrm{MgCl}_{2}$ (Thermo Fisher, catalog number: $\mathrm{AB0359}$ )

18. ATP (Sigma-Aldrich, catalog number: A7699)

19. Phosphocreatine (Sigma-Aldrich, catalog number: P7936)

20. DTT (Sigma-Aldrich, catalog number: D9779)

21. Prestained protein ladder (Thermo Fisher, catalog number: 26616)

22. $15 \%$ Criterion Tris- $\mathrm{HCl}$ protein gel (Bio-Rad, catalog number: 3450019$)$

23. 10x Tris/Tricine/SDS running buffer (Bio-Rad, catalog number: 1610744)

24. 10x Tris/Glycine transfer buffer (Bio-Rad, catalog number: 1610734)

25. Methanol (Thermo Fisher, Fisher Chemical, catalog number: A412-500)

26. Nitrocellulose membrane (Bio-Rad, catalog number: 1620115)

27. TBS-T (Bio-Rad, catalog number: BUF028)

28. BSA (Thermo Fisher, BioReagents, catalog number: BP1600100)

29. Phospho-PKA subtract RRXS antibody (Cell Signaling Technology, catalog number: 9624)

30. Peroxidase Goat Anti-Rabbit IgG (Jackson ImmunoResarch, catalog number: 111-035-144)

31. Clarity ECL (Bio-Rad, catalog number: 1705060)

32. Kinase buffer (see Recipes)

33. IPTG solution (see Recipes) 


\section{Equipment}

1. Refrigerated Centrifuge for Eppendorf tubes (Sorvall, Legend RT, SO-LEGRT)

2. Eppendorf tube heater (Lab Line, Multi Blok Heater, LV40429530)

3. Shaking incubator set to $37^{\circ} \mathrm{C}$ (Thermo Scientific, MaxQ 5000, SHKE50007)

4. Waterbath or drybath set to $37^{\circ} \mathrm{C}$ (Boekel Scientific, Small Water Bath, 290100)

5. Sonicator (Bransonic, Ultrasonic Baths, CPX-952-116R)

6. Rotator for Eppendorf tube (Boekel Scientific, Scientific Rotating Tube Rotator, UX-51202-00)

7. Microcentrifuge (Thermo Scientific, accuSpin Micro 17, 13-100-676)

8. Mini Trans-Blot (Bio-Rad)

9. Mini-PROTEAN Tetra cell (Bio-Rad)

10. ChemiDoc XRS+ System (Bio-Rad)

\section{Software}

1. ImageLab (Bio-Rad)

\section{Procedure}

A. Transformation

1. Thaw BL21 competent cells on ice.

2. Combine $50 \mu \mathrm{l}$ of BL21 cells with $100 \mathrm{ng}$ of plasmid that can be expressed/induced in bacteria (i.e., contains laclq gene sequence which prevents expression until induced by IPTG), in our case, GST vector (pGEX-4T1) with gene of interest (in our case, Profilin-1) and incubate on ice for $30 \mathrm{~min}$.

3. Heat shock mixture at $42{ }^{\circ} \mathrm{C}$ for $45 \mathrm{~s}$ using water bath or heat block.

4. Place mixture back on ice for $2 \mathrm{~min}$.

5. Incubate bacteria mixture in $200 \mu \mathrm{l}$ of LB broth in shaking incubator for $1 \mathrm{~h}$ at $300 \mathrm{rpm}$ and $37^{\circ} \mathrm{C}$ (make sure mixture is not in an airtight tube).

6. Plate all the mixture onto LB agar plate containing appropriate antibiotics, in our case, ampicillin (final concentration $100 \mu \mathrm{g} / \mathrm{ml}$ ) and spread until plate is dry.

7. Incubate at $37^{\circ} \mathrm{C}$ overnight (ensure plate is inverted).

B. Protein induction and extraction

1. Pick a single colony from bacteria plate and grow in $3 \mathrm{ml}$ of $\mathrm{LB}$ broth and appropriate antibiotic overnight (ampicillin final concentration $100 \mu \mathrm{g} / \mathrm{ml}$ ) in bacteria culture tube in shaking incubator at $37^{\circ} \mathrm{C}$ (ensure tube is not airtight).

2. Take $1 \mathrm{ml}$ of this solution and grow in $44 \mathrm{ml}$ of LB broth and appropriate antibiotic (ampicillin final concentration $100 \mu \mathrm{g} / \mathrm{ml}$ ) at $37^{\circ} \mathrm{C}$ in rotating incubator at $300 \mathrm{rpm}$ for $3 \mathrm{~h}$. 
3. Add 1:1,000 $100 \mathrm{mM}$ IPTG to induce expression to mixture and incubate at $300 \mathrm{rpm}$ for another $3 \mathrm{~h}$.

4. Transfer bacteria solution into a $50 \mathrm{ml}$ centrifuge tube and centrifuge bacteria culture for $20 \mathrm{~min}$ at $3,500 \times g$ and $4{ }^{\circ} \mathrm{C}$ to harvest bacteria.

5. Discard supernatant.

6. Resuspend bacteria pellet in $850 \mu \mathrm{l}$ of IP lysis buffer with $50 \mu \mathrm{l} / \mathrm{ml}$ of bacterial protease inhibitor and transfer into a microcentrifuge Eppendorf tube. Bacterial protease inhibitor should be prepared and used fresh each time.

7. Sonicate for $10 \mathrm{~s}$ (no heat), rest on ice for $2 \mathrm{~min}$, and repeat 2 more times. This step is used to shear DNA and break bacteria.

8. Centrifuge at $17,000 \times g$ for $30 \mathrm{~min}$ at $4{ }^{\circ} \mathrm{C}$.

9. Collect supernatant.

Note: Product can be run on a gel and Coomassie stained to confirm protein expression.

C. Protein purification and preparation for kinase treatment

1. Aliquot $\sim 400 \mu \mathrm{l}$ of Glutathione Agarose (GST bead slurry) to Eppendorf tubes.

2. Wash two times with $500 \mu \mathrm{l}$ cold PBS and centrifuge beads down between washes at 8,000 $\times \mathrm{g}$ for $1 \mathrm{~min}$.

3. Wash one time with $500 \mu \mathrm{I}$ IP lysis buffer and centrifuge beads down at 8,000 $\times \mathrm{g}$ for $1 \mathrm{~min}$.

4. Add IP lysis buffer to make $50 / 50$ slurry of beads and IP lysis buffer.

5. Transfer $160 \mu \mathrm{l}$ of this slurry into a new Eppendorf tube and add $540 \mu \mathrm{l}$ of IP lysis buffer to it and $50 \mu \mathrm{l} / \mathrm{ml}$ bacterial protease inhibitor. Bacterial protease inhibitor should be prepared and used fresh each time.

6. Add $300 \mu \mathrm{l}$ of bacteria lysate and rotate using rotating end-over-end rotator at $30 \mathrm{rpm}$ for $2 \mathrm{~h}$ at $4{ }^{\circ} \mathrm{C}$.

7. Centrifuge beads down at $8,000 \times g$ for $1 \mathrm{~min}$ and wash three times with $500 \mu \mathrm{I}$ IP lysis buffer and centrifuge beads down between washes at 8,000 $\times \mathrm{g}$ for $1 \mathrm{~min}$.

8. Wash two times with $500 \mu \mathrm{l}$ kinase buffer and centrifuge beads down between washes at $8,000 \times g$ for $1 \mathrm{~min}$ (leave at 50/50 slurry).

D. Kinase treatment

1. Reconstitute PKA by adding $200 \mu$ of kinase buffer (400UN of PKA comes as a dry pellet) and let sit for $20 \mathrm{~min}$ at room temp, this is your PKA solution.

2. Aliquot 2 Eppendorf tubes with $40 \mu \mathrm{l}$ of GST bead solution containing protein of interest from previous section. One tube will be used as a negative control.

3. Add $5 \mu \mathrm{l}$ of PKA solution to one tube (aliquot the rest of the PKA solution into $5 \mu \mathrm{l}$ and store at $-80^{\circ} \mathrm{C}$ for future use) and $5 \mu$ of kinase solution (i.e., kinase solution with no PKA) to the other. Note that PKA is susceptible to freeze-thaw and loses some activity after the first freeze. The recommended aliquot amount is enough for one treatment group each time and thus no need 
to freeze-thaw. PKA should not be used after being frozen for $>1$ year in $-80^{\circ} \mathrm{C}$.

4. Incubate at $32{ }^{\circ} \mathrm{C}$ for $1 \mathrm{~h}$ using water bath or heat block and mix using vortex every $15 \mathrm{~min}$ to ensure beads are not settled to bottom of tube.

5. Wash two times with $500 \mu \mathrm{IP}$ lysis buffer buffer and centrifuge beads down between washes at $8,000 \times g$ for $1 \mathrm{~min}$ and leave at 50/50 slurry.

6. Aliquot $30 \mu \mathrm{l}$ of solution to a new tube and add $60 \mu \mathrm{l}$ of $1.5 \mathrm{x}$ Laemilli buffer.

7. Boil for $5 \mathrm{~min}$ and centrifuge at $17,000 \times \mathrm{g}$ for $5 \mathrm{~min}$.

8. Transfer supernatant to a fresh microcentrifuge Eppendorf tube.

E. Western blot

1. Load $5 \mu \mathrm{l}$ of protein ladder into $15 \%$ gel and load $30 \mu$ l of protein sample (supernatant from last step in previous section) into adjacent wells.

2. Fill PROTEAN with $1 \mathrm{x}$ running buffer and run at $200 \mathrm{~V}$ for $\sim 45 \mathrm{~min}$ (might be more or less time, run until blue dye from sample buffer runs off the bottom of the gel). These settings were used for our protein-of-interest, settings may be different for other proteins.

3. Transfer protein from gel onto either PVDF or nitrocellulose membrane (we used nitrocellulose) by using Trans-Blot filled with $1 \mathrm{x}$ transfer buffer ( $80 \%$ transfer buffer, $20 \%$ methanol) at $100 \mathrm{~V}$ for $\sim 1.5 \mathrm{~h}$ (might be more or less depending on size of protein of interest). Make sure gel and membrane are placed in the correct orientation, i.e., the gel should be closer to the negative charge source (typically the black colored part of the transfer cassette should be closest to the gel). These settings were used for our protein-of-interest, settings may be different for other proteins.

4. Cut membrane around protein of interest (1-2 ladder bands above and below protein weight) and block with $5 \%$ BSA in TBS-T for 30 min at room temperature with rocking motion. We used an empty microscope coverslip slide box to incubate our membranes (total blocking buffer volume $1.5 \mathrm{ml}$ ). In our case, GST-Pfn1 has a molecular weight of $\sim 41 \mathrm{kd}$, so membrane was cut between 30 and $70 \mathrm{kd}$. Depending on the mass of your protein-of-interest, a different section may need to be cut based off the protein ladder.

5. Incubate overnight $5 \%$ BSA in TBS-T with $1: 1,000$ pRRXS substrate antibody at $4{ }^{\circ} \mathrm{C}$ with rocking motion at $10 \mathrm{rpm}$. Using the same vessel as described previously, we use $1.5 \mathrm{ml}$ of blocking solution and $1.5 \mu \mathrm{l}$ of antibody.

6. Wash with TBS-T one time for $5 \mathrm{~min}$.

7. Incubate with $5 \%$ BSA in TBS-T for $1 \mathrm{~h}$ at room temp with 1:1,000 anti-rabbit peroxidase antibody with rocking motion at $10 \mathrm{rpm}$. Using the same vessel as described previously, we use $1.5 \mathrm{ml}$ of blocking solution and $1.5 \mu \mathrm{l}$ of antibody.

8. Wash 3-4 times with TBS-T for 5 min each wash.

9. Add Clarity ECL solution to membrane and incubate for $1 \mathrm{~min}$ at room temperature.

10. Image membrane (example results shown in Figure 2, PKA treated GST-Pfn1 is detected by pRRXS antibody, using a BioRad ChemiDoc). 


\begin{abstract}
GST-Pfn1
PKA - +

IB: pRRXS

GST-Pfn1 (Coomassie)

Figure 2. pRRXS antibody detects PKA phosphorylated GST-Pfn1. GST-Pfn1 is phosphorylated by PKA and detected by pRRXS antibody whereas kinase buffer solution treated GST-Pfn1 (negative control) is not detected. A Coomassie from this sample is shown as well to illustrate the amount of pulldown to obtain the phospho-band.
\end{abstract}

\title{
Data analysis
}

1. Compare lane from protein sample treated with PKA and sample not treated with PKA.

2. If band intensity is higher in PKA treated sample, the sample has increased phosphorylation as per pRRXS phosphospecific PKA antibody (in our case, in Figure 2, we saw no band intensity to full band intensity after treatment with PKA).

\section{$\underline{\text { Recipes }}$}

1. Kinase buffer

Final concentration of all components is listed below:

$20 \mathrm{mM}$ BES pH 7 (starts as powder, dilute in water and $\mathrm{pH}$ correct until appropriate concentration). This is used as the base of the Kinase buffer

$20 \mathrm{mM}$ EGTA (starts as powder, add into BES solution)

$6 \mathrm{mM} \mathrm{MgCl}_{2}$ (starts as powder, add into BES solution)

5 mM ATP (starts as powder, add into BES solution)

$10 \mathrm{mM}$ phosphocreatine (starts as powder, add into BES solution)

$1 \mathrm{mM}$ DTT (starts as powder, add into BES solution)

2. IPTG solution

Make $100 \mathrm{mM}$ IPTG solution using water and IPTG powder and store at $-20^{\circ} \mathrm{C}$

\section{Acknowledgments}

This work was supported by a grant from the National Institute of Health (2R01CA108607) to PR. David Gau was supported by a National Science Foundation pre-doctoral fellowship (2012139050) and an NIH Cardiovascular Bioengineering pre-doctoral training grant (2T32HL076124 to DG). 


\section{Competing interests}

The authors have no competing interests to report.

\section{$\underline{\text { References }}$}

1. Howe, A. K. (2004). Regulation of actin-based cell migration by cAMP/PKA. Biochim Biophys Acta 1692(2-3): 159-174. 